\title{
PSICOLOGIA SOCIAL COMUNITÁRIA E TEATRO DO OPRIMIDO: RUMOS PARA UMA PRÁXIS TRANSFORMADORA
}

COMMUNITY SOCIAL PSYCHOLOGY AND THE THEATRE OF THE OPPRESSED: ROUTES FOR A TRANSFORMATIVE PRAXIS

PSICOLOGÍA SOCIAL COMUNITARIA Y TEATRO DEL OPRIMIDO: CAMINOS DE UNA PRAXIS TRANSFORMADORA

\author{
Vivian de Andrade Hauck Pinto* \\ Fernando Santana de Paiva**
}

\begin{abstract}
RESUMO
A Psicologia Social Comunitária (PSC) busca desenvolver intervençôes psicossociais que contribuam para a supressão das desigualdades sociais presentes em nossa realidade. Assim como a PSC, o Teatro do Oprimido (TO) propóe uma atividade artística e política comprometida com a transformação da realidade social. Objetivamos apresentar algumas possíveis articulações e contribuições do TO para o campo da PSC, com destaque para as experiências que têm sido realizadas ante as opressões de gênero ainda vivenciadas por inúmeras mulheres no âmbito da sociedade brasileira. Realizamos uma revisão narrativa de literatura, contextualizando dimensões centrais do TO que podem favorecer a atuação dos profissionais da Psicologia diante de situações de exploração e opressão. Consideramos que o TO pode se conformar como uma ferramenta metodológica potente para uma práxis em PSC comprometida com a transformação da sociedade em direção à emancipação política e humana.
\end{abstract}

Palavras-chave: Psicologia Social Comunitária. Teatro do Oprimido. Opressão. Gênero. Emancipação.

\begin{abstract}
Community Social Psychology (CSP) seeks to develop psychosocial interventions that contribute to the suppression of social inequalities within our reality. As well as CSP, the Theatre of the Oppressed (TO) put forward an artistic and political activity committed to social reality transformation. We aim to present possible associations and contributions from the Theatre of the Oppressed to the field of CSP, highlighting lived through events
\end{abstract}

\footnotetext{
Texto recebido em 6 de junho de 2017 e aprovado para publicação em 19 de agosto de 2019.

* Especialista em Saúde do Adulto pelo Hospital Universitário da Universidade Federal de Juiz de Fora (UFJF), graduada em Psicologia pela UFJF. Endereço: Rua Dr. Tarboux, 49, ap. 505 - Granbery, Juiz de Fora-MG, Brasil. CEP: 36010-380. Telefone: (32) 98825-9148. E-mail: vivihauck@gmail.com_

** Professor no Departamento de Psicologia da UFJF, coordenador do Núcleo de Pesquisa sobre Sujeitos, Política e Direitos Humanos (Nupsid). Endereço: Rua José Lourenço Kelmer, s/no - Martelos, Juiz de Fora-MG, Brasil. CEP: 36036-330. Telefone: (32) 99991-5538. E-mail: fernandosantana.paiva@yahoo.com.br
} 
concerning the gender oppression still experienced by countless women within Brazilian society. A narrative literature review was undertaken in order to contextualize central dimensions of TO, which may favour the practice of psychologists in situations of exploitation and oppression. We consider TO as a method and a powerful tool for a CSP praxis committed to the transformation of society towards political and human emancipation.

Keywords: Community Social Psychology. Theatre of the Oppressed. Oppression. Gender. Emancipation.

\title{
RESUMEN
}

La Psicología Social Comunitaria (PSC) busca desarrollar intervenciones psicosociales que contribuyan a la supresión de las desigualdades sociales presentes en nuestra realidad. Así como la PSC, el Teatro del Oprimido (TO) propone una actividad artística y política comprometida con la transformación de la realidad social. Objetivamos presentar algunas posibles articulaciones y contribuciones del TO para el campo de la PSC, con destaque para las experiencias que se han realizado frente a las opresiones de género aún vividas por innumerables mujeres en el ámbito de la sociedad brasileña. Realizamos una revisión narrativa de literatura contextualizando dimensiones centrales del TO que pueden favorecer la actuación de los profesionales de la Psicología ante situaciones de explotación y opresión. Consideramos que el TO puede conformarse como una herramienta metodológica potente para una praxis en PSC comprometida con la transformación de la sociedad hacia la emancipación política y humana.

Palabras-clave: Psicología Social Comunitaria. Teatro del Oprimido. Opresión. Género. Emancipación.

\section{PSICOLOGIA SOCIAL COMUNITÁRIA (PSC) LATINO- AMERICANA: ALGUNS APONTAMENTOS}

\begin{abstract}
$\Lambda$ Psicologia Social Comunitária (PSC) latino-americana remonta a meados da década 60 do século XX, conformando-se, entre outras disciplinas, 1 como um movimento de crítica ao modelo hegemônico de Psicologia como ciência e profissão historicamente conivente com a manutenção da exploração e alienação da classe trabalhadora (Lane, 2012; Parker, 2007). Segundo Lacerda Júnior (2010), predominava, à época, uma visão individualizante, expressão de uma base ideológica única, além da tentativa de reproduzir, de maneira acrítica e descontextualizada, os estudos e teorias elaborados nos EUA e na Europa no contexto latino-americano. De acordo com Montero (2004), esse modelo de Psicologia Social a-histórico mostrava-se insuficiente para compreender a
\end{abstract}


realidade vivenciada pelas pessoas e grupos sociais latino-americanos, resultando em um movimento de contestação e busca por um novo paradigma científico e de intervenção profissional.

A insatisfação com os aportes adotados, a crítica de certa assepsia presente na Psicologia Social hegemônica bem como a necessidade de desenvolvimento de novas práticas nesta área culminaram na denominada crise da Psicologia Social, que se expressou a partir da necessidade de redefinição dos fundamentos teóricos e metodológicos que influenciaram diretamente na construção do campo da PSC em nosso continente (Jiménez-Domínguez, 2004). Por conseguinte, a disciplina passou a incorporar novas fundamentaçōes teórico-metodológicas, nas quais se observam as influências do materialismo histórico-dialético de tradição marxiana, da sociologia crítica e militante de Fals Borda, da educação popular de Paulo Freire, da fenomenologia, entre outras abordagens com caráter crítico, participativo e transformador que floresceram na América Latina (Álvaro, \& Garrido, 2017).

Desde o início, portanto, houve uma predisposição dessa nova disciplina em ampliar e incorporar, em seu arsenal teórico-metodológico, perspectivas que se mostrassem condizentes com as necessidades dos grupos com os quais atuava, tendo como parâmetros centrais a concepção de um sujeito ativo e propositivo, a linguagem como mediação simbólica fundamental, a conscientização como horizonte de atuação e o desenvolvimento de metodologias participativas como estratégia de construção de ações e produção de conhecimento (Martín-Baró, 1998; Montero, 2004; Vieira-Silva, \& Freitas, 2017).

O objetivo central da PSC passou a ser o trabalho comunitário, apontando como preocupação o papel do psicólogo em ações voltadas para a transformação social com vistas à emancipação dos povos oprimidos. Lane (2012) destaca algumas experiências de trabalho comunitário realizado por psicólogas e psicólogos nas décadas de 1970 e 1980, no Brasil, que atuavam no âmbito da saúde mental, educação popular, mas também com grupo de jovens e de mulheres, sendo empregadas diferentes estratégias metodológicas. Todas as experiências, por sua vez, visavam a promover a participação e a resolução dos problemas, tendo os sujeitos como protagonistas da ação.

Assim, o que inicialmente se tratava de um movimento de deselitização da Psicologia, progressivamente caminhou para a estruturação de novos aportes teóricos e metodológicos alinhados com uma perspectiva de sujeito e sociedade constituídos dialeticamente, a partir de um processo social e histórico (Freitas, 2012; Montero, 2004). Conforme sinalizam Martín-Baró (1998) e Borda (2001), está em questão a incapacidade de modelos hegemônicos vigentes no 
campo científico em colaborar nos processos de desideologização e desalienação de sujeitos e grupos sociais, tidas como ações essenciais no âmbito da PSC. Portanto as dimensões da ética e da política são reivindicadas como elementos essenciais nos processos de análise e intervenção da realidade, questionando a pretensa neutralidade requerida no processo de construção de conhecimento, na dicotomia entre sujeito e objeto, e o não compromisso com a transformação da realidade a partir da práxis investigativa.

Assim, a PSC diferencia-se pela centralidade dada ao "trabalho com os grupos, colaborando na formação da consciência crítica e para a construção de uma identidade social e individual orientadas por preceitos eticamente humanos" (Freitas, 2012, p. 59). Montero (2004) ressalta ainda que a PSC latino-americana objetiva romper com o paradigma positivista/neopositivista, enfatizando a importância fundamental da relação entre pesquisador e sujeitos da pesquisa com os quais se constrói o conhecimento. Por essa razão, do ponto de vista epistemológico e metodológico, estratégias participativas, conforme anteriormente sinalizado, que visam à transformação da realidade diante das estruturas de exploração e desigualdades, serão gradativamente preconizadas.

Segundo Cruz, Freitas e Amoretti (2014), é especialmente a PSC, de matriz latino-americana, que se posiciona a favor das maiorias oprimidas, voltando sua práxis para a transformação social e individual a partir da incorporação das culturas populares e da participação social. Nepomuceno, Ximenes, Cidade, Mendonça e Soares (2008) salientam que essa Psicologia se caracteriza ainda pelo fomento à autonomia e emancipação dos sujeitos, e pelo reconhecimento da necessidade de se incluir no estudo psicológico o ponto de vista dos oprimidos. Para Gois (2003), os indivíduos e comunidades podem ser responsáveis pelas construções de suas vidas e, na visão de uma Psicologia Social crítica e contextualizada, esse processo poderia ser potencializado por uma facilitação social que se paute na ação local e na conscientização.

No sentido de desenvolver trabalhos que contribuam para a construção de sujeitos críticos diante da realidade social e que promovam a transformação, na América Latina, das condiçôes de miséria econômica, opressão política e desigualdade social, Nepomuceno et al. (2008) também concordam que a PSC deve orientar-se por métodos participativos que visem à produção de conhecimentos junto aos sujeitos em ação, afirmando o compromisso social do psicólogo e da psicóloga. Na mesma direção, Montero (2004) aponta que essa metodologia se faz importante, pois, ao participar de um fenômeno, ele "passa a ser parcialmente nosso, gerando uma relação peculiar do fenômeno com o sujeito participante, de tal modo que o participante transforma o objeto ou 
o acontecimento do qual participa, e da mesma maneira é por ele, também, modificado" (p. 89).

A PSC, portanto, fundamenta-se a partir de contribuições de diferentes disciplinas comprometidas com a superação das desigualdades sociais e econômicas, traçando paradigmas próprios que orientaram a formulação de novas análises e modelos de intervenção diante da realidade latino-americana. A trajetória já percorrida tem incitado uma série de desafios a respeito da necessidade de ampliarmos o leque de análise e intervenção sem fragilizar os fundamentos que caracterizam o campo. O horizonte ético e político almejado, que visa a se alinhar à transformação e emancipação dos sujeitos oprimidos pela estrutura de exploração do sistema capitalista vigente, necessita de constantes reavaliações acerca das estratégias que têm sido adotadas em campo.

Nessa perspectiva, com vistas ao fortalecimento da pesquisa-ação-participante em Psicologia Social, Campos, Panúncio-Pinto e Saeki (2014) propõem, em seu ensaio, investir no desenvolvimento do teatro do oprimido (TO) como uma potente ferramenta metodológica. Cruz et al. (2014) consideram ainda que pode se tratar de uma contribuição indispensável à Psicologia Social, haja vista a característica interdisciplinar dessa área, que se alinha a outras que se coloquem a serviço da comunidade e que considerem o saber popular como elemento indispensável na produção de saberes e práticas.

Para compreendermos de que forma o TO pode se configurar como um importante aliado nos processos de desideologização e conscientização almejados pela PSC, faz-se imprescindível que conheçamos melhor suas fundamentaçôes teóricas e aplicações práticas. Buscando suprir tal necessidade, a seguir, damos lugar a um breve remonte da construção do TO e sua inserção no contexto brasileiro atual.

\section{O TO DE AUGUSTO BOAL COMO FERRAMENTA DE TRANSFORMAÇÃO SOCIAL}

O TO, assim como a PSC, tem suas raízes na década de 1970, em meio a um cenário político conturbado, caracterizado pela repressão e silenciamento de setores políticos oprimidos da sociedade (Kuhn, 2011). Com a instauração do Ato Institucional no 5 no Brasil, em 1968, e o consequente reforço da censura já instalada pelo golpe militar de 1964, o diretor e dramaturgo Augusto Boal foi condenado à prisão, em 1971, por suas atividades teatrais, e, no mesmo ano, exilou-se na Argentina (Dall'Orto, 2008). Durante seu exílio, Boal criou o teatro do oprimido e assumiu ainda mais um posicionamento crítico ante os cenários 
de opressão, tomando partido dos sujeitos historicamente alijados e apostando no caráter político e transformador do teatro.

Segundo Boal (2009), pelos canais estéticos da palavra, da imagem e do som, e aqui se inclui o teatro, as ideias opressoras se tornam dominantes. Portanto, os mesmos canais deveriam ser usados pelos oprimidos para travar lutas sociais e políticas que almejem a consolidação de uma sociedade sem opressores e oprimidos. Essa relação entre opressores e oprimidos pode ser mais bem compreendida a partir da obra de Freire (1975). Segundo o autor, a contradição opressor-oprimido se instala em uma situação concreta de opressão, sendo que a realidade opressora implica na relação dialética entre opressores e oprimidos, pois, sem estes, os primeiros não existiriam. Por se formarem nessa situação de opressão, na qual são proibidos de ser, os oprimidos acabam por introjetar a sombra dos opressores em si, apresentando-se como seres duais, contraditórios (por muitas vezes, almejando assumir a posição de opressores). A superação dessa contradição ocorre, portanto, quando o oprimido reconhece o opressor em si e luta tanto por sua libertação quanto pela libertação do opressor.

Boal afirma que é preciso reumanizar o espectador, a quem o teatro se acostumou a impor visões acabadas de mundo, visando a romper com o modelo hegemônico do teatro tradicional, no qual atores e plateia se dividem: de um lado, os atores e técnicos detentores de um conhecimento que deve ser aprendido e assimilado e, de outro, a plateia, receptora passiva e acrítica do espetáculo (Campos et al., 2014).

Boal (2009), então, propõe um teatro que se constrói a partir de três principais transgressões. Em primeiro lugar, retira-se o muro antes existente entre atores e plateia, tornando-se possível que o poder da cena seja usado por todos. Nessa direção, vida real e espetáculo teatral passam a ser complementos, sendo este uma etapa, um ensaio que antecede a ação na realidade. Por fim, não mais se distingue artistas de não artistas, já que, para Boal, somos todos artistas de todas as artes, seres humanos capazes de pensar por meios sensíveis (da arte e da cultura). O diretor deixa claro que:

O Teatro do Oprimido jamais foi um teatro equidistante que se recuse a tomar partido - é teatro de luta! É o teatro DOS oprimidos, PARA os oprimidos, SOBRE os oprimidos e PELOS oprimidos, sejam eles operários, camponeses, desempregados, mulheres, negros, jovens ou velhos, portadores de deficiências físicas e mentais, enfim, todos aqueles a quem se impõe o silêncio e de quem se retira o direito à existência plena (Boal, 2005, p. 30).

Para atingir seu objetivo de apoio à luta dos oprimidos, Boal (2005) apresenta diferentes técnicas estruturantes do TO, que se constroem e se relacionam a 
partir da Ética, da Política, da História e da Filosofia. Entre elas, os “jogos” são exercícios voltados a proporcionar a desmecanização dos corpos, que se alienam no processo de inserção no mundo econômico, social e cultural, a partir do cotidiano de exploração registrado no âmbito do trabalho. Tais jogos estão pautados em duas características essenciais para a vida em sociedade: têm leis que devem ser seguidas e, ao mesmo tempo, contam com a liberdade criativa necessária para que a vida (e o jogo) não se torne sinônimo de obediência.

O "teatro de jornal” busca, por sua vez, denunciar a parcialidade dos meios de comunicação, que servirão sempre àqueles que os sustentam economicamente. Já as técnicas que compõem o "arco-íris do desejo" são mais introspectivas e voltam-se para o reconhecimento de que opressões internalizadas têm sua origem nas relaçôes entre o sujeito e sua vida social. O "teatro invisível" realiza uma ação teatral sem aviso, em qualquer lugar onde a trama poderia realmente ocorrer, de forma que esta se confunda com a realidade. Assim, todos os presentes podem intervir na cena, sem haver diferença entre atores e espectadores ao nível de diálogo e poder. Propõe também as "ações diretas", que consistem no uso de artifícios teatrais (como máscaras, danças, etc.), em manifestações de protesto.

Somando-se a essas metodologias, uma das formas mais conhecidas e praticadas do TO é o "teatro-fórum", que pode fazer uso de todas as técnicas teatrais, tendo como principal característica o convite endereçado aos espectadores a entrarem em cena quando identificarem uma situação de opressão, para transformála, com base em estratégias e alternativas por eles mesmos inventadas (Boal, 2005). Os espectadores passam a ser chamados, assim, de "espect-atores", pois se transformam em protagonistas, sujeitos produtores de cultura que podem alterar as cenas propostas nas representaçóes (Sant'Anna, 2002). Por fim, o "teatro legislativo" mescla o teatro-fórum com os procedimentos tradicionais de uma Câmara ou Assembleia, objetivando formular projetos de lei coerentes e viáveis que possam ser submetidos à aprovação de legisladores.

Boal (2005) afirma que "o Teatro do Oprimido, em todas as suas formas, busca sempre a transformação da sociedade no sentido da libertação dos oprimidos. É ação em si mesmo, e é preparação para ações futuras" (p. 19). Quando fala em libertação, Boal se aproxima da conceituação de Martín-Baró (1998), que define o termo como um processo histórico e coletivo que visa à emancipação dos grupos sociais que sofrem opressão a partir de sua autonomização, do resgate de suas potencialidades e do processo de conscientização individual e grupal que advém do fortalecimento dos grupos. Segundo Castro e Dudalski (2015), ao tomarem consciência das condições históricas que engendram relações de dominação/ opressão, os sujeitos apresentam maiores possibilidades de intervir em sua realidade, conformando meios que podem contribuir para a sua emancipação. 
A base para essa emancipação no TO seria o diálogo que acontece entre atores e "espect-atores" na construção das cenas, favorecendo a tomada de consciência e reflexão dos sujeitos acerca de sua realidade e caracterizando o ponto de partida para a ação e a mudança.

Para facilitar esse diálogo, o TO conta com a figura do "curinga", que é um facilitador e coordenador dos grupos em que se insere, mediando o conhecimento dos jogos, das técnicas e do método do TO, além de ser o responsável por estimular os participantes do grupo a contarem suas histórias de opressão e de lutas, auxiliando-os a transformar essas histórias em encenações teatrais (Campos et al., 2014). No teatro-fórum, é o curinga quem elucida e acorda com os participantes as regras do fórum e também quem interrompe as cenas durante as situações acentuadas de opressão, estimulando os "espect-atores" a intervirem e solucionarem as situações apresentadas.

Ao encontraremalternativas, estas devemserencenadase nãoapenas verbalizadas pelos "espect-atores", que assumem o lugar de atores e o protagonismo da cena. Além disso, o curinga é o responsável por alertar os "espect-atores" quanto à proposição de resoluções milagrosas, que não os interessaria por não poderem ser utilizadas na vida real e, portanto, não contribuírem para a transformação desejada. Considerando a bagagem cultural de cada sujeito e as inúmeras formas com que podem contribuir na construção do diálogo, o curinga nunca deve ser centralizador das discussões nem impor ações aos participantes (Castro, \& Dudalski, 2015).

Cumpre ressaltar que as temáticas trabalhadas no TO devem estar relacionadas com o contexto no qual a cena está sendo construída, além de serem identificadas e escolhidas pelos próprios participantes, de forma a contemplar temas cotidianos de interesse coletivo. Boal (2003) salienta que o teatro tradicional estratifica a correlação de forças e violências que constituem a vida social, e que o TO retira das representações essa estratificação e oferece a possibilidade de os "espectatores" analisarem os rituais aos quais estão submetidos diariamente, transitando entre vida e ficção, com foco na transformação de seu futuro.

A discussão e elaboração de diferentes maneiras de intervir nas cenas após a identificação da temática opressora é o que poderá favorecer a transformação social e política da realidade vivenciada pelos "espect-atores", pois poderão decompor as várias situações experienciadas, conformando possibilidades de superação da cadeia de elos oprimidos-opressores que sustenta uma sociedade autoritária (Sant'Anna, 2002). Mesmo que a temática não contemple diretamente todos os "espect-atores", vale ressaltar que Boal (2005) afirma que o TO 
Aumenta o seu poder transformador na medida em que se expande e que entrelaça diferentes grupos de oprimidos: é preciso conhecer não apenas as suas próprias, mas também as opressões alheias. A Solidariedade entre semelhantes é parte medular do T.O. (p. 16).

Segundo Boal (2009), para que uma sociedade pautada por princípios de uma democracia substancial se constitua, é necessária a participação ativa e organizada dos oprimidos na vida social e política. Isso requer um trabalho que auxilie os sujeitos a pensar nas relaçôes desiguais de poder que os envolvem e o TO apresenta-se como uma ferramenta importante para essa criação coletiva de sujeitos com maior potencial crítico e reflexivo acerca de si e do mundo a sua volta, bem como para a construção de saberes e práticas políticas inovadoras, de caráter emancipatório (Campos et al., 2014).

Com o objetivo de ilustrar de que maneira o TO poderia contribuir para a práxis em PSC, a questão da desigualdade de gênero será introduzida a seguir para que sejam exemplificadas, a partir dela, práticas possíveis, de caráter emancipatório, na inter-relação entre essas disciplinas.

\section{PSC, TO E EMANCIPAÇÃO: REPENSANDO A PRÁXIS ANTE AS DESIGUALDADES DE GÊNERO}

De acordo com Silva (2014), desde sua criação, o TO tem se espalhado pelo Brasil e pelo mundo e, haja vista sua abrangência no tratamento de situações e temáticas diferentes, é possível praticá-lo "em uma vila rural africana ou na cosmopolita Nova York" (p. 35). Em razão da potência observada no TO, com vistas à libertação de sujeitos e grupos sociais em situação de opressão e dominação sociopolítica, grupos de TO têm sido criados nos mais diversos contextos: prisões, escolas, centros de atenção psicossocial (CAPS), unidades básicas de saúde (UBS), entre outros. Trata-se de espaços que contam atualmente com a atuação de psicólogos, que têm encontrado uma série de barreiras para efetivar açôes de qualidade e realmente coerentes com essas diferentes realidades (Dimenstein, 2000; Yamamoto, \& Oliveira, 2010).

Para elucidarmos de que maneira o TO poderia contribuir para a práxis da PSC nesses cenários, optamos por enfocar práticas voltadas para a supressão da desigualdade de gênero, que tem sido uma das pautas mais importantes defendidas pela PSC ao longo de sua trajetória. Isso porque grande contingente da população atendida nos serviços nos quais a Psicologia está inserida é composto por mulheres, e a desigualdade de gênero ainda se concretiza em números e símbolos em nosso país. Os dados relacionados às violências sofridas pelas mulheres, a inserção em trabalhos com maior precariedade bem 
como a produção de consciências e subjetividades marcadas pela alienação e silenciamentos, por exemplo, são alarmantes. Tais situações se apresentam no cotidiano das práticas profissionais em Psicologia, culminando em um desafio ético e político do quefazer profissional.

A esse respeito, então, vale retomar que, para Saffioti (1994a), ser mulher não é apenas diferente de ser homem. Ser mulher implica, para além disso, inferioridade, desvalorização e opressão. Opressão esta que faz do oprimido, da oprimida um objeto num processo de exploração-dominação que restringe suas opções. As diferenças entre homens e mulheres existem e, para a autora, por si só, seriam muito bem-vindas. Entretanto o que acontece em sociedade é a construção da desigualdade com base nas diferenças.

A autora chama atenção para a concepção de gênero como "relação entre sujeitos historicamente situados" (Saffioti, 1994a, p. 55) e identifica como fonte da situação de opressão não o homem (como indivíduo ou categoria social, ainda que personifique o opressor), mas sim o padrão dominante de relação de gênero. Este, por sua vez, regula e normatiza também as relações homem-homem e mulher-mulher, não sendo possível que homens nem mulheres se situem fora dessa relação de poder. Ou seja, a violência que uma mulher comete contra outra seria produzida pelo gênero tanto quanto a violência que um homem incide sobre uma mulher.

Nessa perspectiva, Araújo (2000) afirma que:

O conceito de gênero surge da tentativa de compreender como a subordinação é reproduzida e a dominação masculina é sustentada em suas múltiplas manifestações, buscando incorporar as dimensões subjetiva e simbólica de poder, para além das fronteiras materiais e das conformações biológicas (p. 68).

Na mesma direção, Almeida, Silva e Machado (2014) apontam que, com a abordagem de gênero, reconhece-se a hierarquia de poderes na sociedade, contrapondo-se ao enfoque hegemônico que naturaliza as desigualdades entre os sexos e distancia as mulheres de sua emancipação política e social. Sob o manto da cultura dominante, conformou-se um quadro em que a mulher é inserida em uma posição de subalternidade, o que legitimaria sua invisibilidade social e política, culminando na adoção de valores sem prestígio ao que é denominado como feminino, enquanto o mundo masculino teria como base natural o poder e o reconhecimento social.

Segundo Cisne (2014), é pela imposição da ideologia dominante, patriarcalracista-capitalista, que o processo de naturalização da dominação de gênero ocorre. Essa naturalização dificultaria a consciência de que a desigualdade entre os 
sexos é determinada por interesses socialmente construídos e, consequentemente, a percepção por parte dos indivíduos das relações de dominação e exploração como tais. Mesmo quando essas relações são percebidas, a naturalização das desigualdades se torna um obstáculo diante da possibilidade de os indivíduos pensarem e agirem de forma transformadora, já que acreditam ser incapazes de alterá-las. No caso das mulheres, é importante percebermos que a naturalização da dominação de gênero faz com que muitas delas reproduzam sua condição de subserviência como algo inato ou biológico.

Pensando numa emancipação tanto da mulher quanto da humanidade, Araújo (2000) considera que esse processo, assim como o de dominação, perpassa relações de interação, conflito e poder entre homens e mulheres, o que faz com que o problema deixe de ser apenas das mulheres e passe a necessitar de alteraçôes nos lugares, valores e práticas dos atores sociais em geral. Além disso, uma ação política que vise a um projeto emancipatório não poderia ignorar as outras clivagens que permeiam as relações sociais, a saber, de classe social e raça/ etnia, que devem ser trabalhadas simultaneamente à de gênero, considerando suas dimensões próprias e inter-relacionadas.

Quanto a esse processo de enfrentamento, Saffioti (1994b) e Arruzza (2015) consideram que as relações de gênero hegemônicas não são determinantes e que uma parcela das mulheres consegue romper com a relação dominada/dominante, quando passa a ter consciência dessas relações. A partir dessa conscientização, muitas dessas mulheres passam, inclusive, a lutar pela ampliação de sua condição de sujeito de direito, o que pode representar subversões na ordem instituída. É no sentido de facilitar uma tomada de consciência, a partir de uma reflexão crítica da realidade, que o TO pode ser utilizado como uma metodologia com potencial de fortalecer a luta das mulheres não somente por seus direitos, mas também por sua emancipação política e humana.

De modo a estimular a participação ativa e o protagonismo das camadas oprimidas da sociedade na transformação da realidade, por meio de projetos que priorizem o diálogo, foi criado, em 1986, o Centro de Teatro do Oprimido do Rio de Janeiro (CTO-Rio). O CTO-Rio é, atualmente, um centro de pesquisa e disseminação do TO e desenvolve projetos nas áreas da educação, do sistema prisional, dos movimentos sociais, da saúde mental, entre outros. Considerando a busca por açôes que favoreçam a supressão da desigualdade de gênero, há que se destacar, entre os trabalhos do CTO, o Laboratório Madalena - Teatro das Oprimidas e o grupo popular de teatro do oprimido Marias do Brasil, por serem formados por e para mulheres. O Laboratório Madalena busca investigar, mediante a experiência cênica, quais são as especificidades das opressões enfrentadas por mulheres e de que forma elas podem ser superadas. 
Desenvolvida em diversos países, a experiência busca transformar a realidade a partir do diálogo estabelecido com os "espect-atores" acerca das opressões e das violências contra o corpo da mulher. No Rio de Janeiro, o grupo Madalenas Rio e o Núcleo Jovens Madalenas Maré são exemplos de desdobramentos dessa experiência.

Já o grupo popular de teatro do oprimido Marias do Brasil foi formado em 1998 por dez trabalhadoras domésticas, todas chamadas Maria. Por meio de projetos como Encenando Direitos Humanos e Maria Luta por Lei Justa, o grupo luta pelas trabalhadoras domésticas e por seus direitos trabalhistas. Em seu livro O teatro como arte marcial, Boal (2009) revisita uma das experiências do grupo que deixa claro o impacto do TO na vida de uma de suas participantes e na (re) construção de sua identidade. Após apresentar-se no Teatro da Glória, Rio de Janeiro, uma das mulheres do grupo relata ao diretor que uma "boa empregada doméstica" aprende a ser invisível e que, pela primeira vez, por causa do teatro, a família para a qual trabalhava (presente na plateia) a tinha visto e ouvido por quem realmente era. Emocionada, ela termina dizendo que, após a apresentação, viu uma mulher no reflexo do espelho, onde antes apenas conseguia ver uma empregada doméstica, invisível.

O deslocamento dessa mulher para uma nova forma de se perceber e de se colocar no mundo é um importante exemplo de como o TO pode ser uma ferramenta de promoção de novos processos de subjetivação e conhecimentos a partir da participação popular e da criação coletiva, sendo, por isso, cada vez mais utilizado em áreas acadêmicas e profissionais como a Educação, a Comunicação e a Psicologia (Campos et al., 2014).

Em relação ao campo da Psicologia, como previamente apontado, acreditamos que o TO encontra forte aderência na PSC, por também pautar sua ética na tomada de partido das classes subalternas e metodologicamente reconhecer a "necessidade de participação popular para a construção de práticas libertadoras e promotoras de mudança” (Ximenes, Cidade, \& Silva, 2016, p. 165). Além disso, a PSC se aproxima do TO por adotar como modelo um sujeito ativo e de infinita potencialidade para utilizar ferramentas materiais e simbólicas, relacionando-se com a realidade de forma dialética ao construir sua subjetividade a partir dela, ao mesmo tempo em que é capaz de transformá-la (Pizzinato, 2014).

Segundo Montero (2000 apud Pizzinato, 2014), a prática psicológica deve comprometer-se com o fortalecimento dos grupos desprivilegiados, fomentando a organização de uma resistência e a luta contra os modelos hegemônicos opressores, entre outros, de ciência, de saúde mental, de orientação sexual e de relações de gênero. A complexidade das situações naturalizadas de dominação 
e opressão às quais as mulheres estão submetidas exige a atenção da PSC pelas inúmeras implicações que têm na vida e na construção identitária desses sujeitos. Portanto se faz necessária a busca por ferramentas metodológicas contextualizadas que consigam alcançar meios de favorecer a transformação de sua realidade social. Levando-se em consideração que o TO assume a mesma posição ética que a PSC ante os oprimidos, pode-se perceber a possibilidade de, em conjunto, fortalecerem a luta pela emancipação das mulheres.

Nessa direção, corroborando a perspectiva de que o TO possase configurar como uma ferramenta potente no trabalho voltado para romper com a desigualdade de gênero, Oliveira e Araújo (2014) apostam no teatro-fórum como instrumento metodológico, com a proposta de promover discussões sobre a violência contra a mulher, numa abordagem de pesquisa participativa em Psicologia. Para tanto, foi construída uma esquete acerca da temática, apresentada para uma cooperativa de catadores e catadoras de material reciclável e uma associação de catadores e catadoras de material reciclável. As autoras apontam que foi possível observar como as mulheres participantes da pesquisa conseguiram problematizar os discursos hegemônicos de gênero, criando rupturas com os papéis sociais antes assumidos como naturais.

Com base nesse relato de pesquisa e das experiências de grupo realizadas pelo CTO-Rio com e para mulheres, consideramos pertinente afirmar a possibilidade de se empregar o TO como estratégia metodológica, a fim de edificarmos uma Psicologia que se proponha a uma práxis que almeje promover a superação das mais diversas opressões e sofrimentos vividos por diferentes sujeitos sociais, mediante uma participação ativa e o compartilhamento de suas experiências antes silenciadas (Oliveira, 2013).

\section{CONSIDERAÇÕES FINAIS}

Tendo em vista a realidade brasileira de desigualdade social, política e econômica, e as relações de opressão e dominação que a permeiam, este artigo buscou apresentar preliminarmente um meio de potencializar as possibilidades de análises e intervenção da PSC, com vistas à sua maior inserção na realidade social e à assunção de um compromisso ético de transformação social que almeje uma sociedade que se fundamente em justiça e liberdade.

Com enfoque na opressão vivida pelas mulheres ante uma realidade hegemônica de desigualdade de gênero, que as afeta das mais diferentes maneiras, faz-se uma aposta no TO como uma ferramenta metodológica participativa potente que possa aproximar cada vez mais a PSC de uma práxis que favoreça a emancipação 
das mulheres. Nesse sentido, consideramos que o TO pode ser uma importante ferramenta a ser empregada por psicólogos em seu quefazer profissional, com reais possibilidades de conformar diferentes experiências estéticas entre os sujeitos participantes das ações. Ademais, trata-se de uma perspectiva coerente com os princípios da Psicologia Comunitária latino-americana, ocupada em fortalecer processos de transformação radical da realidade social.

É importante salientar que, neste artigo, não foram esgotadas as possibilidades de contribuição do TO para a práxis psicológica e aponta-se também para a necessidade de realização de maiores estudos e pesquisas que utilizem o $\mathrm{TO}$ em sua metodologia, de modo a contribuir para uma discussão mais fundamentada acerca de suas potencialidades e possibilidades de aplicação dentro do campo da PSC. 


\section{REFERÊNCIAS}

Almeida, L. R., Silva, A. T. M. C., \& Machado, L. S. (2014). O objeto, a finalidade e os instrumentos do processo de trabalho em saúde na atenção à violência de gênero em um serviço de atenção básica. Interface, 18(48), 47-59. Recuperado a partir de: http://www.scielo.br/scielo.php?script=sci_arttext\&pid=S1414$32832014000100047 \& \operatorname{lng}=$ en \&nrm=iso\&tlng=pt

Álvaro, J. L., \& Garrido, A. (2017). Psicologia social: perspectivas psicológicas e sociológicas. Porto Alegre: Artmed.

Araújo, C. M. O. (2000). Marxismo, feminismo e o enfoque de gênero. Crítica Marxista, 11, 65-70.

Arruzza, C. (2015). Considerações sobre gênero: reabrindo o debate sobre patriarcado e/ou capitalismo. Revista Outubro, 23, 33-58. Recuperado a partir de: http://outubrorevista.com.br/wp-content/uploads/2015/06/2015_1_04_ Cinzia-Arruza.pdf

Boal, A. (2003). O teatro como arte marcial. Rio de Janeiro: Garamond.

Boal, A. (2005). Teatro do oprimido e outras poéticas políticas. ( $\left.7^{\mathrm{a}} \mathrm{ed}.\right)$. Rio de Janeiro: Civilização Brasileira.

Boal, A. (2009). A estética do oprimido. Rio de Janeiro: Garamond.

Borda, O. F. (2001). Aspectos teóricos da pesquisa participante: considerações sobre o significado e o papel da ciência na participação popular. In C. R. Brandão (Org.), Pesquisa participante. (pp. 42-62). São Paulo: Brasiliense.

Campos, F. N., Panúncio-Pinto, M. P., \& Saeki, T. (2014). Teatro do oprimido: um teatro das emergências sociais e do conhecimento coletivo. Psicologia e Sociedade, 26(3), 552-561.

Castro, I. C., \& Dudalski, S. S. (2015). Contribuições de Paulo Freire e Augusto Boal no trabalho com o teatro em uma rede protetiva às mulheres em situação de violência. Linguasagem, 23, 201-216. Recuperado a partir de: http://www. linguasagem.ufscar.br/index.php/linguasagem/article/view/69/106

Cisne, M. (2014). Feminismo e consciência de classe no Brasil. São Paulo: Cortez.

Cruz, L. R., Freitas, M. F. Q., \& Amoretti, J. (2014). Breve história e alguns desafios da Psicologia social comunitária. In J. C. Sarriera, \& E. T. Saforcada 
(Org.), Introdução à Psicologia comunitária: bases teóricas e metodológicas. (pp. 76-96). Porto Alegre: Sulina.

Dall'Orto, F. C. (2008). O teatro do oprimido na formação da cidadania. Fênix - Revista de História e Estudos Culturais, 5(2), 1-16. Recuperado a partir de http://www.revistafenix.pro.br/PDF15/Artigo_03_ABRIL-MAIOJUNHO_2008_Felipe_Campo_Dall_Orto.pdf

Dimenstein, M. (2000). A cultura profissional do psicólogo e o ideário individualista: implicações para a prática no campo da assistência pública à saúde. Estudos de Psicologia, 5(1), 95-121. Recuperado a partir de http://www. scielo.br/scielo.php?script=sci_arttext\&pid=S1413-294X2000000100006

Freire, P. (1975). Pedagogia do oprimido. (3a ed). Rio de Janeiro: Paz e Terra.

Freitas, M. F. Q. (2012). Psicologia na comunidade, psicologia da comunidade e psicologia (social) comunitária: práticas da psicologia em comunidade nas décadas de 1960 a 1990, no Brasil. In R. H. F. Campos (Org.), Psicologia social comunitária: da solidariedade à autonomia. (pp. 44-65). Petrópolis: Vozes.

Gois, C. W. L. (2003). Psicologia comunitária. Universitas: Ciências da Saúde, 1(2), 277-297.

Jiménez-Domínguez, B. (2004). La Psicología social comunitaria em América Latina como Psicología social crítica. Revista de Psicología, 13(1), 133-142.

Kuhn, M. L. W. (2011). Boal e o teatro do oprimido: o espect-ator em cena na educação popular. (Dissertação de Mestrado). Programa de Pós-Graduação em Educação nas Ciências, Universidade Regional do Noroeste do Estado do Rio Grande do Sul, Ijuí.

Lacerda Júnior, F. (2010). Notas sobre o desenvolvimento da Psicologia Social Comunitária. In F. Lacerda Jr. \& R. S. L. Guzzo (Orgs.), Psicologia \& sociedade: interfaces no debate sobre a questão social. (pp. 19-41). Campinas: Alinea.

Lane, S. T. M. (2012). Histórico e fundamentos da psicologia comunitária no Brasil. In R. H. F. Campos (Org.), Psicologia social comunitária: da solidariedade à autonomia. (pp. 17-34). Petrópolis: Vozes.

Martín-Baró, I. (1998). Psicología de la liberación. Madri: Trotta.

Montero, M. (2004). Introducción a la Psicología comunitaria: desarrollo, conceptos y processos. Buenos Aires: Paidós. 
Nepomuceno, L. B., Ximenes, V. M., Cidade, E. C., Mendonça, F. W. O., \& Soares, C. A. (2008). Por uma psicologia comunitária como práxis de libertação. Psico, 39(4), 456-464.

Oliveira, E. C. S. (2013). O teatro-fórum pode auxiliar na discussão da violência contra a mulher dentro da universidade? In Z. Ligiéro, L. Turle, \& C. Andrade (Org.), Augusto Boal: arte, pedagogia e política. (pp. 137-158). Rio de Janeiro: Mauad X.

Oliveira, E. C. S., \& Araújo, M. F. (2014). O teatro fórum como dispositivo de discussão da violência contra a mulher. Estudos de Psicologia, 31(2), 257-267. Recuperado a partir de http://www.scielo.br/pdf/estpsi/v31n2/a11v31n2.pdf

Parker, I. (2007). Revolution in Psychology: alienation to emancipation. Londres: Pluto.

Pizzinato, A. (2014). Psicologia da libertação. In J. C. Sarriera, \& E. T. Saforcada (Org.), Introdução à Psicologia comunitária: bases teóricas e metodológicas. (pp. 113-136). Porto Alegre: Sulina.

Saffioti, H. I. B. (1994a). Posfácio: conceituando gênero. In H. I. B Saffioti, \& M. Muñoz-Vargas. Mulher brasileira é assim. (pp. 271-283). Rio de Janeiro: Rosa dos Tempos.

Saffioti, H. I. B. (1994b). Violência de gênero no Brasil atual. Estudos Feministas, 2, 443-461. Recuperado a partir de https://periodicos.ufsc.br/index.php/ref/ article/viewFile/16177/14728

Sant'Anna, C. (2002). Poder e cultura: as lutas de resistência crítica através de duas experiências teatrais. In D. Mato (Org.), Estudios y otras prácticas intelectuales latinoamericanas em cultura y poder. (pp. 265-275). Buenos Aires: CLACSO.

Silva, F. J. R. (2014). Uma história do teatro do oprimido. Aurora: revista de arte, mídia e politica, 7(19), 23-38. Recuperado a partir de https://revistas.pucsp.br/ index.php/aurora/article/view/17313/14298

Vieira-Silva, M., \& Freitas, M. F. Q. (2017). Psicologia (social) comunitária: rupturas, avanços, diálogos e consolidações. In M. Vieira-Silva, M. D. Vecchia, F. S. Paiva, L. F. V. Cardoso, J. C. Mazini, \& M. N. M. Machado (Orgs.), Democracia, política e Psicologia social: rupturas e consolidaçôes. (pp. 87-106). Florianópolis: Abrapso. 
Ximenes, V. M., Cidade, E. C., \& Silva, G. R. G. (2016). Pesquisas em Psicologia nos contextos de pobreza: para que e para quem? In V. M. Ximenes, B. B. Nepomuceno, E. C. Cidade, \& J. F. Moura Jr (Org.), Implicaçôes psicossociais da pobreza: diversidades e resistências. (pp. 165-183). Fortaleza: Expressão.

Yamamoto, O. H., \& Oliveira, I. F. (2010). Política social e Psicologia: uma trajetória de 25 anos. Psicologia: teoria e pesquisa, 26, 9-24. 